\title{
Assessment of ultraviolet radiation exposure of welders working in Shahrud City, Iran, 2014
}

\author{
Vatani J, $\mathrm{PhD}^{1^{*}}$, Ghasemzadeh Kolagar H, BSc ${ }^{2}$, Raei M, MSc ${ }^{3}$ \\ 1-Assistant Prof., Dept. of Ergonomics, School of Public Health, Hamedan University of Medical Sciences, Hamedan, Iran. \\ 2-Students Research Committee, School of Public Health, Shahroud University of Medical Sciences, Shahroud, Iran. \\ 3-Faculty Member, Health Research Center, School of Public Health, Baqiyatallah University of Medical Sciences, Tehran, \\ Iran.
}

Background: Farmers and welders who work in open spaces and are exposed to direct sunlight are often exposed to sunlight radiation on the neck and head. Thus, they may be afflicted with various types of skin cancer. The aim of the present study was to investigate the amount of UV exposure in welders working in Shahrud City, Iran.

Materials and Methods: This cross-sectional, descriptive, analytical study was conducted from 9 a.m. to 3 p.m. in indoor environments on all welders working in Shahrud City $(n=50)$ in 2014. An ultraviolet radiation (UVR) meter was used to measure UVR and the instrument was calibrated and utilized using factory instructions. Moreover, All data obtained through the demographic checklist and self-reporting, and information related to UVR exposure were entered into SPSS software and analyzed.

Results: The results showed that average UVR exposure with personal protection was $0.27 \pm 1.15$ $\frac{\mathrm{j}}{\mathrm{cm}^{2}}$, average UVR exposure without personal protection was $4.14 \pm 1.69 \frac{\mathrm{j}}{\mathrm{cm}^{2}}$. In addition, skin radiation exposure amount was $2.55 \pm 1.54 \frac{\mathrm{j}}{\mathrm{cm}^{2}}$. There was no significant statistical relationship between presence of disease, and radiation expsoure with or without protection euqipment and on the skin of welders $(\mathrm{P}>0.05)$.

Conclusions: This study indicated that UVR is among the main harmful factors in occupational environments. Welders are vulnerable to skin and eye disease due to UVR exposure. UV exposure in welders working in Shahrud City is below the threshold value; therefore, it can cause injury and damage to the welders. Furthermore, insurance status, daily radiation exposure amount, received radiation exposure amount, and use of protection equipment had no significant relationship with incidence of disease in welders.

Keywords: Welding, Ultraviolet Rays, Eye Diseases, Skin Diseases, Insurance.

\section{Introduction}

Electromagnetic radiation with 100 to $400 \mathrm{~nm}$ wavelength is called ultraviolet radiation (UVR). Different wavelengths of UVR have different effects $(1,2)$. The main natural source for generating UVR is the sun. Artificial sources of UVR are UV lamps and the welding industry (2). The rate of UVR from the sun which reaches the earth's surface is reduced considerably by the ozone layer in the atmosphere. The strength of UVR reaching the Earth is increased by the thinning of the ozone layer (3). Tanned skin is one of the primary effects and early aging is a long-term effect of UV exposure (3, 4). Farmers and workers who work in open spaces and are exposed to direct sunlight are often exposed to sunlight radiation on the neck and head, and

\footnotetext{
*Corresponding author: Javad Vatani, Dept. of ergonomics, School of Public Health, Hamedan University of Medical Sciences, Hamedan, Iran. Email: jvatani@gmail.com
} 
thus, they may be afflicted with various types of skin cancer $(2,5)$.

In the study by Kim et al. in South Korea, it was shown that macular degeneration in welders is not related to age, rather is it mostly developed due to exposure to the welding arc (3). In a study on 102 white men, no relationship was found between the damage to the inner layer of the cornea among welders and exposure to UVR (6). In the study by Hang, it was shown that UVR in aluminum welders places the skin and eyes at great risk (7). Studies indicate that UVR exposure with energy above $10 \mathrm{j} / \mathrm{cm}^{2}$ causes acute responses, including skin erythema, and long-term (chronic) exposure to UVR resulting from sunlight leads to skin cancer $(3,5,8)$. The study by Peng indicated that the permanent use of eye protection equipment in welding can prevent any harm to the corneal layer (9). Furthermore, many relationships have been found between UVR exposure and skin deformation (9).

The study by Vatani et al. illustrated that welders in the Sarcheshmeh Copper Complex, Kerman, Iran, were exposed to low levels of UVR (UV $=0.09 \mathrm{j} / \mathrm{cm}^{2}$ ), and thus, the probability for emergence of disease due to UVR was low (10).

The study by Birt showed that, in addition to exposure to UVR, welders are also exposed to welding fumes, chronically and acutely, which leads to various diseases including respiratory tract irritation, bronchitis, changes in lung function, and lung cancer (11). Welders are vulnerable to skin and eye diseases due to contact with a broad range of UVR (12-16). The aim of this study was the investigation of the rate of UV exposure in welders working in Shahrud City, Iran, in 2011.

\section{Materials and Methods}

This cross-sectional, descriptive, analytical study was conducted from 9 a.m. to 3 p.m. in indoor environments on all welders working in Shahrud City $(n=50)$ in 2014. Shahrud is a City in Semnan Province, Iran. Shahrud is situated about an altitude of $4413 \mathrm{ft}(1345 \mathrm{~m})$. It is located at latitude $36^{\circ} 25^{\prime} \mathrm{N}$ and longitude $055^{\circ} 01^{\prime} \mathrm{E}$ and some 410 kilometers to the east of Tehran. Now, it is the second largest City of Semnan Province, and also its county has the same position in the province.

The ultraviolet radiation meter (model EX-4, Hagner Photometric Instruments Ltd, UK) was used for measuring UVR and the instrument was calibrated and utilized using factory instructions. The UVR meter is a direct reading instrument which shows results directly after measurement.

First, using a checklist, demographic information were obtained from welders including age, years of service, insurance, marital status, any disease of the eyes and skin, and use of personal protection equipment. Considering results of medicine, lacrimation, irritation, and redness of the eye and ocular symptoms as well as tanned and dry skin as the result of welding were recorded as the symptoms of skin disease caused by a welding job $(1,10)$. In addition, the electrode used for welding was 2-5 $\mathrm{mm}$ in diameter with a voltage of 21-24 $\mathrm{V}$ and current of 60 to 210 A.

Subsequently, UV exposure on the hand, in front of personal protection equipment, on the face, and behind the protection equipment was measured as follows. First, welders were asked to weld in their usual work conditions and the UVR meter was placed exactly on their hand in a way that the sensor was facing the welding process, and the obtained number was recorded. Then, the instrument was placed in front of the protection equipment with the sensor facing the welding process, and the amount of radiation was recorded. Finally, the UVR meter was placed inside the protection equipment and on the face so that the sensor is facing the welding process and UVR rate was recorded (10).

Finally, all information obtained through the demographic checklist and self-reporting, and information related to UVR exposure were entered into SPSS software (version 13, SPSS Inc., Chicago, IL, USA). Data were analyzed 
using indexes of mean, SD, number and percentage, $95 \%$ confidence level, and Kruskal-Wallis test and the Pearson correlation coefficient. Furthermore, the significance level was considered as 0.05 in all tests (10).

\section{Results}

Average age and working experience of welders were $39.46 \pm 11.89$ and $16.9 \pm 11.66$ years, respectively. In total, $86 \%$ (43 cases) of the welders were insured and $80 \%$ (40 cases) were married. Among them, 14 cases (28\%) used eye and face protection equipment (welding shield and goggles), 29 cases (58\%) used the welding shield and gloves (to protect hands and face), and 6 cases (12\%) used all personal protection equipment (shield, gloves, and goggles). Only 1 case (2\%) of welder did not use any personal protection equipment. Average UVR exposure with personal protection was $0.27 \pm 1.15 \frac{\mathrm{j}}{\mathrm{cm}^{2}}$, average UVR exposure without personal protection was 4.14 $\pm 1.69 \frac{\mathrm{j}}{\mathrm{cm}^{2}}$, and skin radiation exposure was $2.55 \pm 1.54 \frac{\mathrm{j}}{\mathrm{cm}^{2}}$. Moreover, $30 \%$ (15 cases) of welders suffered from eye and skin diseases; $53.3 \%$ (8 cases) had eye disease, $33.3 \%$ (5 cases) had skin disease, and $13.3 \%$ ( 2 cases) had both diseases. Average age of individuals with disease $(46.27 \pm 7.3)$ was significantly higher than healthy individuals (36.54 \pm 12.35) $(\mathrm{P}=0.007)$.

Furthermore, there was a statistically significant relationship $(\mathrm{P}=0.030)$ between working experience and disease. Results indicated that in $80 \%$ of cases (40 cases) skin radiation exposure was above the permitted level. There was a $21.9 \%$ prevalence of disease in subjects with daily radiation exposure duration of less than 8 hours. The prevalence of desease was $44.4 \%$ among subjects with daily exposure duration of above 8 hours. However, this difference was not statistically significant. Disease prevalence in welders with radiation exposure of less and more than the standard limit was $20 \%$ and $32.5 \%$, respectively, which was not a significant difference. Moreover, no statistically significant relationship was observed between the use of personal protection equipment and use of welding equipment and presence of disease in welders (Table 1).

Table 1: Risk factors related to disease incidence

\begin{tabular}{l|c|c|c}
\hline \multirow{2}{*}{ Variable } & \multicolumn{2}{|c|}{ Incidence of disease } & \\
\cline { 2 - 4 } & Yes & No & P \\
\hline Radiation exposure with protection equipment & mean \pm SD & mean \pm SD & \\
\hline Radiation exposure without protection equipment & $0.05 \pm 0.04$ & $0.36 \pm 1.37$ & 0.39 \\
\hline Radiation exposure on the hand & $2.78 \pm 1.56$ & $4.00 \pm 1.75$ & 0.36 \\
\hline
\end{tabular}

* Permitted UVR exposure limit in welding is $1 \frac{\mathrm{j}}{\mathrm{cm}^{2}}$

Average radiation exposure with and without protection equipment as well as average skin exposure among individuals with skin disease were $0.05 \pm 0.038,4.2 \pm 1.21$, and $2.85 \pm 1.39$ $\frac{\mathrm{j}}{\mathrm{cm}^{2}}$, rspectively. These values were $1.24 \pm$ $0.3,4.13 \pm 1.77$, and $2.5 \pm 1.58 \frac{\mathrm{j}}{\mathrm{cm}^{2}}$, respectively. There was no statistically significant relationship between presence of disease and radiation expsoure with and without protection equipment and on the skin of wleders $(\mathrm{P}>0.05)$.

\section{Discussion}

UVR is among the major harmful factors in occupational environments (1-4). It is 
especially important in jobs such as welding and working while exposed to sunlight. Excessive UVR exposure threatens the health of workers and results in various diseases. Tanned skin is one of the primary effects and early aging is a long-term effect of UV exposure (3-5).

Welders are vulnerable to skin and eye disease due to UVR exposure (12). The current study investigated the amount of UV exposure in welders working in Shahrud City and its relationship with skin and eye disease.

Considering the findings, UVR in the welding industry causes eye or skin diseases, or both groups of diseases. As results indicate, there is a significant relationship between age and working experience of welders, and these diseases. The incidence of eye disease due to UVR in welders was $53.3 \%$, incidence of skin diseases was $33.3 \%$, and incidence of both groups of diseases was $13.3 \%$.

Results showed that in $80 \%$ of (40) welders, skin radiation exposure is higher than the permitted level which supports findings by Vatani. In addition, insurance status, daily radiation exposure amount, received radiation exposure amount, and use of protection equipment had no significant relationship with incidence of disease in welders.

Received radiation amount in Shahrud welders was higher than the permitted level (recommended standard for exposure is 1,000 $s$ and less than $1 \frac{\mathrm{j}}{\mathrm{cm}^{2}}$ ), which leads to disease and damage to welders. This supports findings of the study by Chiung-ya peng, but it does not support findings by Vatani.

Moreover, reviewed UVR amount in the use of welding equipment for cutting metals is above the standard level for welding equipment $(\mathrm{P}=0.004)$. Specified electrodes with $3-5 \mathrm{~mm}$ diameters generate more UVR compared to electrodes with other diameters. This is consistent with findings of the studies by Antonini, and Vatani.

Using the Pearson correlation coefficient $(\mathrm{P}=$ 0.003), a direct relationship was observed between voltage and received radiation amount (0.497). In other words, increasing the voltage of welding instruments increases received UVR. This finding is consistent with that of the studies by Kim EAKBG, Emil Obalak, and Vatani.

\section{Conclusion}

According to results, $32.6 \%$ of welders who were insured suffered from diseases resulting from UVR exposure, which shows high expenditures of compensation and treatment of welders' diseases by the insurance companies. If exposure is reduced in welders to below the permitted level using appropriate methods, not only will their health be insured, but also useful working continuation, increased productivity, and reduced compensation costs will observed.

Considering the findings of the current research, appropriate clothing, masks, and specific shield with suitable protection level should be used during welding operation. Moreover, voltage should be set at an appropriate level (increasing voltage increases UVR received from welding instrument) and electrodes with 3-5 $\mathrm{mm}$ diameters, which generate more UVR than other electrodes, should not be used.

The investigation of the incidence of diseases resulting from UVR and UVR exposure in other industries and farmers is also recommended.

\section{Acknowledgement}

We would like to thank the Research Department of Shahroud University of Medical Sciences, Iran, for funding this study as a research plan.

Conflict of interest: Non declared

\section{References}

1. Lim HW, James WD, Rigel DS, Maloney ME, Spencer JM, Bhushan R. Adverse effects of ultraviolet radiation from the use of indoor tanning equipment: time to ban the tan. J Am Acad Dermatol 2011; 64(4):e51-60. 
2. D'Orazio J, Jarrett S, Amaro-Ortiz A, Scott T. UV radiation and the skin. Int J Mol Sci 2013; 14(6):12222-48.

3. Kim EA, Kim BG, Yi CH, Kim IG, Chae CH, Kang SK. Macular degeneration in an arc welder. Ind Health 2007; 45(2):371-3.

4. Ratanaprasatporn L, Neustadter J, Weinstock MA. Scientific developments in indoor tanning and melanoma. J Am Acad Dermatol 2011; 64(4):783-5.

5. Turaka K, Shields CL, Shah CP, Say EA, Shields JA. Bilateral uveal melanoma in an arc welder. Graefes Arch Clin Exp Ophthalmol 2011; 249:141-4.

6. Antonini JM. Health effects of welding. Crit Rev Toxicol 2003; 33(1):61-103.

7. Na HR, Heisler G, Nowak DJ, Grant RH. Modeling of urban trees' effects on reducing human exposure to UV radiation in Seoul, Korea. Urban Forestry \& Urban Greening 2014; 13(4):785-92.

8. Doughty MJ, Oblak E. A clinical assessment of the anterior eye in arc welders. Clin Exp Optom 2005; 88(6):387-95.

9. Peng CY, Lan $\mathrm{CH}$, Juang YJ, Tsao TH, Dai YT, Liu HH, et al. Exposure assessment of aluminum arc welding radiation. Health Phys 2007; 93(4):298-306.
10. Vatani J, Raei M, Asadi M. Assessing the ultraviolet exposure level in welding workers of Sar-Cheshmeh copper complex. Zahedan Journal of Research in Medical Sciences 2013; 15(4):76-7.

11. Birt B, Cowling L, Coynp S. UVR reflections at the surface of the eye. $J$ Photochem Photobiol B 2004; 77(1-3):71-7.

12. Oblak E, Doughty MJ. Chronic exposure to the ultraviolet radiation levels from arc welding does not result in obvious damage to the human corneal endothelium. photochem photobiol Sci 2002; 1(11):857-64.

13. Häder DP, Helbling EW, Williamson CE, Worrest RC. Effects of UV radiation on aquatic ecosystems and interactions with climate change. Photochem Photobiol Sci 2011; 10(2):242-60.

14. de Gruijl FR. Skin cancer and solar UV radiation. Eur J Cancer 1999; 35(14):2003-9.

15. Taylor HR, West SK, Rosenthal FS, Muñoz B, Newland HS, Abbey $\mathrm{H}$, et al. Effect of ultraviolet radiation on cataract formation. $\mathrm{N}$ Engl J Med 1988; 319(22):1429-33.

16. Ohnaka T. Health effects of ultraviolet radiation. Ann Physiol Anthropol 1993; 12(1):1-10. 